\section{THE EPIDEMIOLOGY OF INFLUENZA.} BY

M. GREENWOOD, Captain R.A.M.C.(T.F.), Lister instituTe AND Ministry OF MUNitions.

IT is a fortunate circumstance that, in addition to tho able monograph of Leichtenstern, ${ }^{1}$ we liave historical contribu. tions to the study of influenza from the pens of such epidemiologists as Hirsch, Haeser, and Creighton. These authors, from coucordant testimony extending over nearly seven hundred years, established the following propositions relative to influenza observed up to the modern statistical period.

1. Primary influenza is a uniform disease. In the emphatic words of Hirsch, "it has at all times and in all places borne a stamp of uniformity in its contiguration and in its course such as almost no other infective disease has."

2. Primary influenza is independent of both climatic and meteorological conditions. Fipidemics have occurred in literally every quarter of the globe, and have commenced at every period of the year, with high or low temperatures, steady or changeable weather, much or little atmospheric moisture.

Dissecting the notion of uniformity, we remark that primary epidemics have been regularly characterized by (a) a tendency to become pandemic; (b) a fatality which is far slighter than the severity of the symptoms would lead us to expect-a feature shared with dengue, which disease has often been confused with influenza, although now known to be entirely distinct from it; $(c)$ a special incidence upon persons in the prime of life. The above described features are rarely missed in the historical accounts.

In contrast to the above, we find three questions which were discordantly answered.

I. The first was that of periodicity. Hirsch's denial of any periodicity sufficiently distinct to be revealed by a mere cursory examination of the records must be endorsed; but it is proper to remark that periodicity in the strict sense of the term can only be disclosed by a somewhat elaborate mathematical investigation carried out upon long series of numerical data; neither the technical method nor suitable statistics were at the disposal of our predecessors.

II. The second vexed question was whether influenza were a wind-borne infection. Hirsch remarked that the proven fact of pandemics progressing against the direction of prevailing winds was unfavourable to the hypothesis, and no recent evidence is opposed to his conclusion.

III. 'The last disputed point, namely, the contagiousness of influenza, is now decided, and in the opposite sense to that of Hirsch, who concluded his discussion of the matter with the words, "We shall find it hard to discover any reason for counting influenza among the contagious or conmunicable diseases."

The modern period opens with the pandemic of 1889-90, upon which Leichtenstern and Parsous ${ }^{2}$ are excellent authorities.

I will very briefly refer to their non-numerical results, since I wish to direct attention more particularly to some statistical points. Parsons was able to bring together concordant testimonies as to the ordinary mode of development of the epidemic. His most signiticant result was to show that epidemic influenza does not really originate in a mass attack. A mass attack, indeed, forms an invariable liuk in the chain of events, but scattered individual cases are antecedent. This observation removed the most formidable objection to a belief that influenza is contagious, and it is easy to understand why we discover no confirmation in historical records. In such epidemic diseases as plague the preceding sporadic cases are recorded because their high fatality leads to inclusion in bills of mortality; but in consequence of the very low fatality of primary epidemic influenza early mortality records are wanting. The mass pinenomenon strikes the imagination of the recorder and an illusion of suddenness and simultaneity is produced. Further evidence of contagion is afforded by the following observations :

1. The almost complete immunity of such segregated

* Contribution to the discussion at the Royal society of Mledicine, November 13 th, 1918 .

groups as the Dogger fishermen and lighthouse keepers duriug 1889-90.

2. The relative imm anity of prisoners and other inmates of institutions, particularly in comparison with the staff.

3. The tendency of the epidemic to begin in crowded centres, or, in any particular locality, to be clated from the holding of a public meeting.

No single one of these observations is logically decisive, but, like all epidemiological questions, this must be decidert upon broad issues of greater or less probability. 'The general body of evidence creates a presumption in favour of the theory of contagion. Some assertions which, if true, would have demonstrated the inadequacy of the hypothesis have been disproved; such are the alleged simultaneous occurrence of a very large number of cases without previous exposure to possible sources of infection, or the suggestion that influenza extends uniformly in space with velocity greater than that of human transport.

It would be unscientific to discard the hypothesis of direct personal infection because particular instances, respecting which all the facts cannot be known, lend it no support. +

I now pass to the numerical side of the epidemiology.

The fundamental characteristics of a primary epidemio of influenza-and by primary I understand an epidemic occurring in any locality after a succession of years nearly free from the disease-are a very high attack rate and an approximately symmetrical evolution in time. The number of cases increases rapidly to a maximum and then decreases to the endemic level at a rate but little slower than that of its increase; the graph of the epidemic is an almost symmetrical curve; the fatality is low, rarely more than 1 per cent. of cases. These extremely important features of rapid and symmetricai evolution can only be properly displayed when the number of cases, not merely deaths, has been recorded.

Diagram 1 exhibits such data of the 1889-90 epidenic, and is condensed from Leichtenstern's record of daily notifications in Munich. For the London epidemic wo



Diagram 1.



have only deaths, so that the symmetry is obscured, the tail of the curve lengthening out. Diagram 2 gives the intluenza mortality in London for January, 1890, the primary epidemic, also the course of the succeeding epidemics in London, which culminated in the early summer of 1891 and the winter of 1891-92.

+ The most famous instance is the outbreak of influenza in January, 1890, in the remote and isolated parish of Bradwell-on. Sea, in Essex. 'he facts, as set out by the medical otticer of health, will be found in Parsons's report (C. 6387, pp. 74-75), and were emphasized by my.coreporter to the Section of Hygiene and Preventive Medicine at the Internationnl Congress of Medicine, London, 1913 (see Sticker, Ueber a bhïugen (sect. 18, Int. Cong. Med.) 
In contradistinction to a primary epidemic, a secondary epidemic affects a relatively small proportion of the population, is slower in reaching its maximum, and thereafter declines slowly and irregularly-more slowly than it increases; its distribution in time is asymmetrical, and there is less concentration around the maximum. Further, a secondary epidemic is characterized by a vastly higher fatality than a primary epidemic. The influenza period of 1889-94 gave us four epidemics: the primary sym. metrical epidemic of Dccember, 1889, to February, 1890. the secondary asymmetrical and much more fatal epidemi of the spring and summer of 1891 ; a third epidemic in the antumn and winter of 1891-2; and a fourth from November, 1893, to January, 1894. The third epidemic showed some tendency to revert to the primary type in respect of symmetry (see Diagram 2), while the fatality rate partook of the character of the secondary epidemic." Creighton writes:

That which chiefly distinguishes the influenza of the end of the nineteenth century from all other invasions of the disease the nineteenth century from all other invasions of the disease first recurrence having been more fatal than the original outfirst recurrence having been more fatal than the original outbreak, and the second recurrence more fatal (in London at least, than the first. 'The closest scrutiny of the old records,
including the series of weekly bills of mortality issued by the including the series of weekly bills of mortality issued by the
parish clerks of London for nearly two hundred years, discovers no such recurrences of influeuza on the great scale in successive seasons. ${ }^{3}$

He would be a bold man who challenged the accuracy of Creighton upon a point of historical scholarship, and I have only to suggest that there are faint indications of increased mortality in years following primary epidemics of influenza prior to the nineteenth century. Thus 1675 was a year of primary epidemic influenza, fully described in Sydenham's Observationes Medicae.

The nature of the succeeding constitutions is not clear, but the deaths "within the bills" for 1676 were considerably more numerous thau in 1675, although small. pox, fever, and "griping of the guts" were noticeably less fatal.

In the Epistola Responsorin $(1,54)$ the epidemic con. stitution of 1679 is described as a recurrence of that of 1675-that is, as having the features of primary epidemic influenza. In the five following years intermittents prevailed, and in one (1684) the mortality much exceeded that of 1679, although the deaths from small-pox were fewer. Again, a hundred years later, in 178'2, there was a famous summer epidemic of influenza in London which save rise to much discussion. The London mortalities in 1782 and 1783 were, however, almost equal, wheu the swall-pox deaths (which were nearly three times as numerous in 1783 as in 1782) are subtracted from the total mortality of each year.

Whether these vague indications are sufficient to permit of our thinking that the epidemic constitution of 1889-94 was not entirely unprecedented is disputable. But the contrast of the latter period with the preceding single (pidemic of $1847-48$ is striking; that was a primary cpidemic withont important sequelae.

We have now to consider whether our experience this vetu is concordant with that of the early nineties, a reversion to the earlier type, or a new phenomenon.

We are fortunately in possession of excellent statistical data for reaching a conclusion. The most suitable for my object are those of the Royal Air Force, the Medical Department of which has placed epidemiologists under an obligation by introducing an efficient system of recording the progress of the disease. The representatives of the force will no doubt publish a complete study ; I have only to refer to special features to which $I$ have paid attention. l)iagram 3 displays the course of events in the summer and autumn. The abscissae are weeks; the ordinates, which are expressed in terms of the number of cases recorded in the worst week, show the incidence upon al per'sonuel at home. The full line is the Munich epidemic of 1889-90, expressed in the same unit and superimposed upon the other graph, the worst week of the earlier opidemic being made to correspond with the worst week of the late outbreak.

The general similarity of the two is unmistakable. When * 'These points are well displayed in Dixey's monograph, Eividemic infl ternea, Oxford, 1892.

lid ve cap. 5eaths were attributed by Sxdenham, who did not practitioners - "In other virtues, to the incompetence of his brother ot facile sa nabilem in periculosum ac saepe letalen transformabant." we add that the fatalities were equally low and the attack rates equally high, we shall have no doubt at all that we are

$$
100
$$
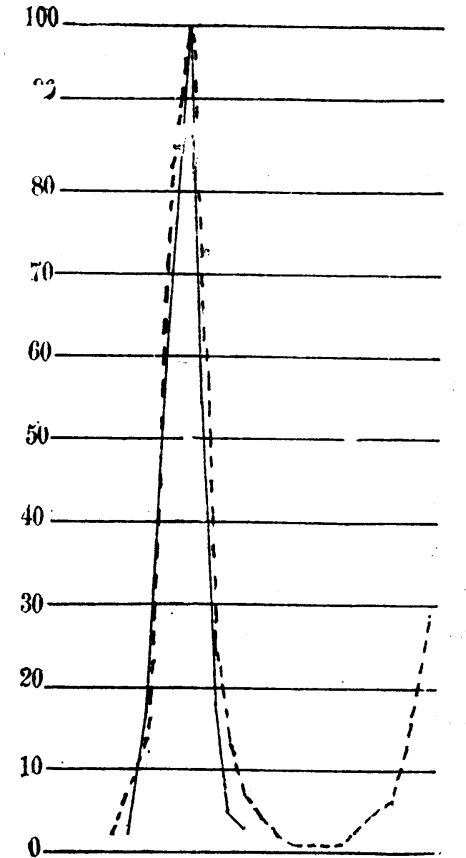

Diagram 3: - Munich. - - - R.A.l.

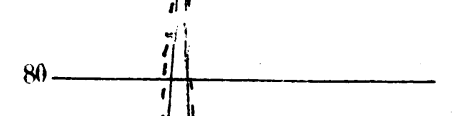
dealing with congruent epiderniological events.

For a testimony of the course of events in a civilian population, I submit data compiled for national munition factories situated in different parts of the country. Here we had to adopt a different statistical basis which is shown in the table. Using this now unit, the course of the epidemic is seen to be similar to that displayed in the R.A.F. I illus trate it in Diagram 4, which takes the record of the particular factory ased down to the end of October. As a matter of interest, I may add that when the per. centages plotted are re. duced to terms of real hours, one finds that the summer epidemic cost about thirty-six hours a head of the whole munition-making population, so that the loss of output to the community was equivalent to that of about four working days.

I believe that the evidence just presented establishes a substantial identity between the summer outbreak of 1918 and the primary wave of 1889-90. We do not need to appeal to any new factor arising out of the war to account for it.

I next consider the secondary epidemic which we are now experiencing. Evidently our knowledge of the events in 1891 would lead us to feel no surprise at the emergence of a secondary ware, although we could not be sure that the precedent of 1847 would not be followed. + Judging from deaths alone, the in terval between the decline of the 1889-90 primary and the emergence of the 1891 secondary was quite four. teen months in London, but the third epidemic was separated from the second by a much shorter interval. (in London about five months), $\$$ in parts of the country little if any longer than has elapsed this year.

Confining myself to in. cidence for a moment, I take up again the Air Force records (Diagram 3). The right hand end of the diagram is plotted in terms of the unit used before

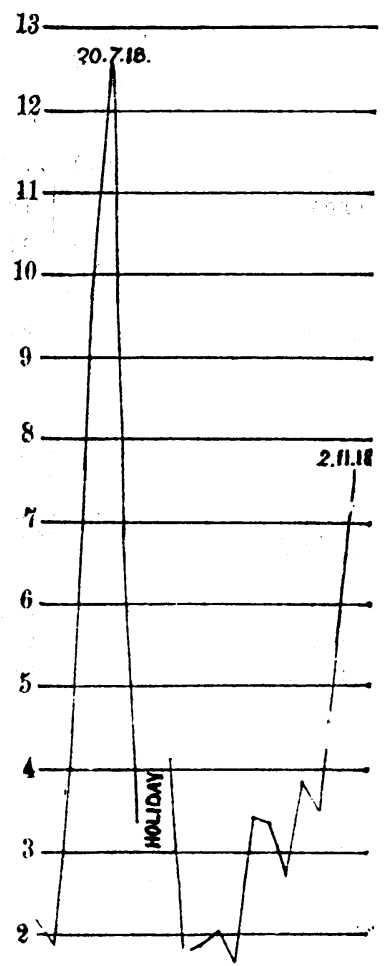

\section{DiAgram 4.-Factory J. M (employing 1,451 men).} -namely, the worst week of the summer epidemio taken as 100-so the records of the two outbreaks are

$\mp$ The course adopted by the Modical Department of the Ministry of Munitions was to circularize during the first week of October th managers of hostels, warning them that a renowal of the epidemi aight occur. that the individual attacks wonld probably be mor adoquate reatiment

The ferval between secondary snd tertiary was only some 6 wo hetween this vear's two evidemic: 


\begin{tabular}{|c|c|c|c|c|c|c|c|c|}
\hline \multirow[b]{2}{*}{ Date. } & \multirow{2}{*}{ Factory. } & \multicolumn{2}{|c|}{$\begin{array}{l}\text { Maximum } \\
\text { Reached. }\end{array}$} & \multicolumn{2}{|c|}{$\begin{array}{l}\text { Return to } \\
\text { Normai.* }\end{array}$} & \multirow{2}{*}{ 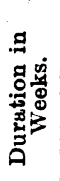 } & \multirow{2}{*}{ 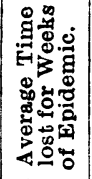 } & \multirow{2}{*}{ 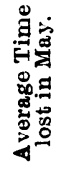 } \\
\hline & & 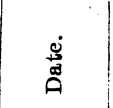 & 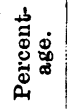 & 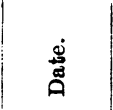 & 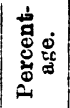 & & & \\
\hline $\begin{array}{c}1918 . \\
\text { June } 1\end{array}$ & A. $\mathrm{W}$ & $\begin{array}{l}1918 . \\
\text { July } 6\end{array}$ & 11.78 & July 20 & 4.42 & 7 & 7.42 & 3.22 \\
\hline : & B. $\mathbf{M}$ & ", & 12.86 & July 27 & 5.09 & 8 & 9.10 & 5.93 \\
\hline , & C. $\mathbf{W}$ & June 29 & 22.66 & " & 9.90 & 8 & 17.33 & 14.13 \\
\hline June 8 & B. $\mathrm{w}$ & , & 20.91 & ,. & 9.55 & 7 & 15.79 & 7.92 \\
\hline.$"$ & A. $\mathbf{M}$ & June 22 & 7.93 & July 20 & 480 & 6 & 5.43 & 1.72 \\
\hline , & D. $\mathrm{w}$ & ," & 21.53 & , & 8.21 & 7 & 15.46 & 7.22 \\
\hline$"$ & E. $\mathbf{M}$ & , & 14,26 & .. & 5.03 & 7 & 8.27 & 5.59 \\
\hline ," & F. W & July 6 & 21.41 & Aug. 3 & 8.78 & 8 & 13.86 & $\S$ \\
\hline June 15 & E. W & , & 16.27 & July 20 & 9.23 & 5 & 14.06 & 11.32 \\
\hline ." & D. $\mathrm{MI}$ & ,. & 19.71 & Aus. 27: & 904 & 11 & 16.09 & 7.06 \\
\hline , & G. $\mathbf{W}$ & ,. & 22.06 & ," & 10.08 & 6 & 17.42 & 8.47 \\
\hline , & C. $\mathbf{M}$ & .. & 21.95 & ," & 8.29 & 6 & 16.62 & 11.83 \\
\hline ", & H. M & . & 15.91 & $"$ & 8.80 & 6 & 13.12 & 8.59 \\
\hline , & I. $\mathbf{M}$ & June 22 & 21.96 & " & 7.47 & 6 & 1213 & 4.12 \\
\hline " & I. W & , & 32.95 & July 20 & 4.95 & 5 & 17.39 & 8.82 \\
\hline , & J. IV & July 27 & 16.78 & Aug. 3 & 9.32 & 7 & 11.42 & 5.01 \\
\hline$"$ & F. $\quad \mathbf{M}$ & July 6 & 15.31 & " & 11.53 & 7 & 1367 & $\S$ \\
\hline$"$ & K. $\mathrm{M}$ & June 29 & 22.13 & July 20 & 880 & 5 & 15.78 & 6.16 \\
\hline$"$ & K. W & July 6 & 1842 & July 27 & 3.96 & 6 & 13.66 & 5.11 \\
\hline " & L. W & July 20 & 21.05 & Aug. 3 & 6.86 & 7 & 13.72 & 4.45 \\
\hline June 22 & G. $\mathbf{M}$ & June 29 & 17.68 & July 27 & 5.23 & 5 & 11.42 & 6.93 \\
\hline$"$ & H. IV & July 6 & 21.95 & $"$ & 990 & 8 & 16.97 & 13.06 \\
\hline$"$ & M. W & June 29 & 25.37 & Aug. 3 & 5.64 & 6 & 12.74 & 2.87 \\
\hline$"$ & M. $\mathbf{M}$ & July 6 & 15.33 & ", & 5.51 & 6 & 9.85 & 4.23 \\
\hline " & N. W & July 20 & 10.42 & July 29 & 2.41 & 5 & 590 & 4.25 \\
\hline June 29 & o. $\mathbf{M}$ & July 6 & 9.48 & Aug. 3 & 700 & 5 & 9.49 & 6.57 \\
\hline$"$ & J. $\quad \mathbf{M}$ & July 20 & 1625 & $"$ & 4.82 & 5 & 10.01 & 5.04 \\
\hline$"$ & P. II & No work & & July 27 & 5.93 & 4 & $-t$ & 5.18 \\
\hline July 6 & Q. W & Aug. 3 & 8.23 & Aug. 10 & 6.49 & 5 & 6.94 & 5.39 \\
\hline$"$ & N. $\mathbf{M}$ & July 20 & 19.79 & Aug. 3 & 0.35 & 4 & 10.15 & 3.45 \\
\hline$"$ & P. W & No work & & July 27 & 5.43 & 3 & 6.99 & 2.81 \\
\hline July 20 & R. $\mathrm{W}$ & Aug. 3 & 20.87 & Sept. 7 & 4.48 & 7 & 1686 & 4.34 \\
\hline
\end{tabular}

* These figures are affected in some cases by the disturbance due to holidays. ** Duration affected by holidays. + Incomplete for worst week. \$ No returns.

directly comparable. One sees at once that we are dealing with a quite different epidemiological fact. Let us ignore for a moment the question of symmetry and consider that of concentration. As I have pointed out, the salient features of a primary epidemic are a rapid and quasi-symmetrical evolution. Consequently the frequency is very closely concentrated around the maximum.

To express this numerically, the summer epidemic of 1918 in the Royal Air Force included nearly 80 per cent. of the total incidence within the three weeks containing the maximum, and the Munich epidemic included just over 80 per cent. within the same limits. Now if the current epidemic has reached its maximum, not more than 65 per cent. of the incidence will probably be so concentrated, and the duration will therefore be longer than in the summer; if, as suggested by the ratio of the last two ordinates, the maximum is not yet attained, then the quota of the three worst weeks is likely to be still swallev and the complete duration still longer.

'The diagram of factory sickness leads to the same inference, which is that, from the standpoint of prevalence, the present is a typical secondary epidemic congruent with that of 1891. But this way of looking at the facts leaves ot of account the appreciably higher fatality we are experiencing. Here again part of the explanation is afforded by goneral epidemiological considerations.
If the view of the relations between primary and secondary epidemics of influenza just outlined be accepted, it follows that, per accidens, we have had ill luck in 1918 and bad good luck in 1889. In 1889 the primary epidemic reached us in the winter, the secondary appeared in a more clement season, actually skipping a year; but since the epidenuic constitution of a secondary influenza period is pneumonic - the old-fashioned nomenclature is usefulwe sliould anticipate a relatively low mortality in a summer secondary, and a relatively bigh mortality in a winter secondary; one remembers the extreme instance of plague, the change of constitution in the Great Death of 1348-49 between summer (bubonic) and winter (pneumonic). This general hypothesis goes some way to explain the situation, but we also have accessory factors peculiar to the war. I believe that gross over. crowding and fuel restrictions are of particular importance here. That food rationing has had anything to do with the epidemic seems to me improbable. The epidemiological indications of disease engendered by want of food are sufficiently distinct. Prior to an epidemic explosion there is always a slow but fairly steady increase of morbidity. Examination of records which have been maintained in the Ministry of Munitions with the object of detecting any ill effect of rationing, has revealed none of the pathognomonic signs of scarcity (Diagrams 5 and 6 ).

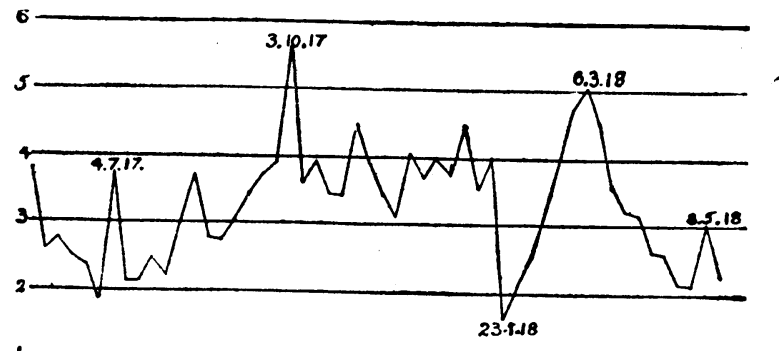

Diagram 5.-Men. Rations and sickness rates; one year.

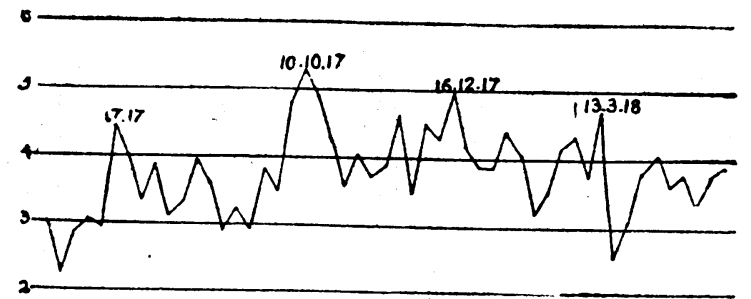

DIAGRam 6.-Wonen. Rations and sickness rates; one year.

When to this is added the experience of influenza amongsi our own adequately fed, and amongst other superabun. dantly nourished troops, we shall have little reason to regard food shortage as a probable factor.

It appears, then, that the origin of the summer epidemic must be explained upon such epidemiological principles as will account for the primary wave of 1889-90, that the current outbreak is in pari materia with that of 1891 , its excessive mortality being mainly due to the accident of season, aided by the special circumstances of overcrowding and fuel shortage which are due to the war. In a word, this is not essentially a war epidemic.

If what has just been said be worthy of acceptance merely as a working hypothesis, some important conclusions follow :

It is unlikely that the present epidemic will be extinguished for some time, and it is likely that a recrudescence will be observed next year. Further epidemiological research is necessary to unravel the cause groups re. sponsible for shaping the epidemic forms. I have used the terms symmetry, asymmetry concentration, in a popular sense and have not introduced the analytical refinements of modern statistics. Such refinements could not be applied to the older mortality data with any hope of success, but it is otherwise with the material now in process of accumulation. A careful dissection of the epidemic frequency distributions should enable us to separate the epidemiological factors, work which, colre. lated with that of the bacteriologists, must precede any 
but a crudely empirical system of prophylaxis. The recent researches of Sir Ronald Ross and of Dr. Brownlee illus. trate the importance of numerical epidemiology, and the final solution of the influenza problem will only be ob. tained by the harmonious co-operation of epidemiologists and bacteriologists.

'Nothnagel's Specielle Pathologie, Band IV. Thiel I, pp. 1-195. 2 Local Government Board Reports: C. 6387 (1891), and C. 705i (1893). 3 Croighton's History of Epidemics in Britain, vol. ii, p. 397 . 'C C t the evidence summarized by Greenwood and Thompson, Proceedings
Section of Epidemiology and State Medicine, Royal Society of Medicine, April, 1918.

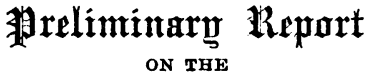

\section{INFLUENZA EPIDEMIC AT BRAMSHOTT IN SEPTEMBER-OCTOBER, 1918.}

$$
\text { BY }
$$

C. E. COOPER COLE, B.A., M.B.'Tor., LIEUT.-CoLONEL C.A.M.C.,

Officer in Charge Medical. Division, No. 12 Canadian Gentrat HOSPITAL, BRAMSHOTT.

\section{INTRODUCTORY NOTE}

jux

Coloner R. D. Rudolf, C.B.E., M.D., F.R.C.P., Consulting Physician to the Canadian Forces in England.

Colonel Cols and his officers have had a most extensive experience of influenza in the recent epidemic. The notes of the complications of th? disease are very valuable-for example, the frequent rupture of the recti abdominales muscles. I have not been as much struck as the writer was by the fetor in the disease.

The frequency of relapses has been very noticeable; these relapses liave often occurred several days (in one case ten (days) after the temperature had originally re turned to normal. Such relapses occurred while the patients were still in bed, and hence were not due to any chill or exhaustion.

The mortality of the cases admitted to hospital works out at 7.25 per cent., and of all the cases reported in the camp 3.6 per cent., which is noticeably higher than in the original epidemic of the spring, but low as compared to some reports of recent ravages. Death was practically always due to respiratory complications.

Character of the OUtbreak.

After the outbreak of influenza in May and June our hospital had very occasional admissions of cases of this disease until the later part of September. On Septem. ber 24th three cases reported, and on the succeeding days 9, 17, 24, 26, a maximum of 174 being reached on October 5th. Since then the epidemic has been abating, and on November 7 th the total admissions for influenza were only 12

In all, 2,247 cases have passerl through hospital out of about 4,500 cases in the area; 163 cases had a fatal termi. nation, the period of illness varying fion five to twentyseven days, and the jathological changes affecting the lungs or in yocardium.

The usual history was of sudden onset of chilly feeling, headache, general aching, and weakness with dizziness; then cough and tightmess in the chest, with glairy sputum, and very frequently epistaxis. Objectively an indescribable fetor. was present in even the mildest cases, and, in the very severe, was almost overwhelming. It disippeared before complete recovery of the patient. 'The febrile course of the disease varied from tiventy-four hours to fifteen days' continuous fever, running as high as $106.6^{\circ}$ inclined to be remittent, and ending by lysis. The types might be considered as:

(a) Mild, temperature becoming normal within three to seven days without disturbance of pulse or respiration. Considerable weakuess persisted, and renal irritation was usually present. Even these mild cases showed a tendency to tachycardia on slight exertion in convalescence.

(b) 'The next grade of severity ran a course of five to twelve days with high fever, marked cyanosis or livid pallor, and rapid respiration-all evidences of severe toxaemia, with very few signs in the chest except of diffuse emphysema or of bronchitis down to the capillary tubes, with sputum moderate to copious, glairy to muco-purulent to yellow-green purulent, and becoming dirty sanguineo. purulent to dark clotted blood. In some cases bright red blood was expectorated, as much as $4 \mathrm{oz}$. at a time; one case, for which no other cause could be found, proved fatal from haemoptysis. A number of these cases proved fatal, and showed peribronchial induration or patchy central bronchopneumonia.

(c) The most severe types were either (1) primary marked bronchitis with profound toxacmia, rapidly becoming pneumonic, or (2) a primary toxic type as in (b) above, the temperature falling to normal or thereabouts for one to six days and then rising again to a secondary serere pneumonic course, with a frequently fatal issue.

Spectal Clinical and Pathological Features.

Some peculiar clinical and pathological features were noticed in this series of cases. In the first place very marked fetor of the exhalations, so offensive in some cases as to render careful chest examination difficult, was pathognomonic.

The Respiratory 'Tract.

In the respiratory tract there was marked congestion from the nares to and through the pleura. The respiratory rate was frequently out of all proportion to pulse or temperature, fifty to the minute being often maintained for a week, with pulse not above 110 . Rhinitis with epistaxis, often recurrent, was present in over one-third of the cases. Pharyngitis, tonsillitis, laryngitis, and tracheitis (often pseudo-membranous, causing dyspnoea, stridor, and inspiratory retraction of lower ribs), bronchitis, and bronchiolitis.

The cough was of several types-(1) explosive, (2) paroxysmal, closely resembling pertussis, and in a few cases was (3) "brassy." The bronchitis, at first dry, afterwards usually became moist with abundant muco-purulent sputum. The inflammatory condition extending deeper, lobular and pseudo-lobar pneumonia of variable extent developed. Fibrinous, sero-fibrinons and sero-puralent pleurisies occurred, 16 cases showing definite empyemata, streptococcic more frequently than pneumococcic on direct sinear. Compensatory empliysema often developed out of proportion of areas of consolidation, and in 12 cases with severe chest signs interstitial emphysema developed in the mediastinum, and so extended up to the malar eminences and down over chest and abdomen. Only one such case recovered. Most of these cases showed definite small pulmonary abscesses either in continuity with the mediastinum or parietes. No cases of pneumothorax were observed. Areas of haemorrhage into the lung tissue were so often seen, in various stages from recent occurrence to liquefaction, that this condition might be considered almost pathognomonic of the disease. One very toxic case died from suditen onsct of pulmonary oedema on the eighth day with very little cousolidation. Several cases showed only "purulent bronchitis." Four cases showed activated pulmonary tuberculosis. 'Two of these became miliary, two miliary of the lungs, and one of the latter developed tuberculous basal meningitis.

\section{Circulatory Effects.}

The early cyanosis was toxic rather than asphyxial. The tongue itself was often of dark indigo and the whole body of a lilac tint for several days before death. Pulse usually relatively slow-for example, respirations 40, pulse 88 , temperature $104^{\circ}$-and often dicrotic. The systolic blood pressure in previously healthy young adults often ran below $100 \mathrm{~mm}$., and diastolic could hardly be estimated. In only one case was recent pericarditis found, and no recent endocarditis. The main change was myocardial, but rarely accompanied by right heart dilatation. 'The circulatory failure was often of very sudden onset, a pulse of 100 of good quality becoming 140 within two hours, and ceasing in less than four. The blood itself clots readily though purpuric eruptions ivere noted in some cases, as well as haemorrhages into the lungs and muscles. Phlebitis, brachial and saphenous, was not rare. There was usually a leucopenia, 2,400 to 9,000 white blood corpuscles per c.cm. in purely toxic cases, and even in 